06

\title{
Влияние барьерных эффектов на межфазных границах на динамическое рассеяние света в нематическом жидком кристалле
}

\author{
(С) Л.П. Амосова, Д.С. Бойков, Д.П. Щербинин
}

Университет ИТМО,

197101 Санкт-Петербург, Россия

e-mail: I_amosova@mail.ru

\section{(Поступило в Редакцию 12 декабря 2016 г. В окончательной редакции 4 марта 2017 г.)}

\begin{abstract}
Исследована зависимость интенсивности динамического рассеяния света в нематическом жидком кристалле (ЖК) с отрицательной диэлектрической анизотропией ЖК-440 от напряженности постоянного электрического поля при различных условиях на межфазной границе. Показано, что возникающие на границах раздела потенциальные барьеры влияют не только на интенсивность рассеяния, но могут качественно изменять форму зависимостей: кривые оптического пропускания в направлении падающего луча могут иметь при определенной напряженности поля минимум, выше которого ячейки вновь полностью просветляются. Такой аномальный ход кривых пропускания объясняется уменьшением проводимости ячеек ниже критического значения с ростом напряжения за счет увеличения сопротивления области объемного заряда на обратно смещенном переходе экстрагирующего электрода. Показано, что причиной высокого сопротивления ячеек при малых напряжениях, помимо низкой концентрации примесей в ЖК, может являться низкая эмиссионная эффективность инжектирующего электрода и слабое сродство к электрону экстрагирующего электрода.
\end{abstract}

DOI: 10.21883/JTF.2017.09.44913.2131

\section{Введение}

Сущность эффекта динамического рассеяния света в жидких кристаллах (ЖК) заключается в образовании локальных неоднородностей в слое ЖК, которые рассеивают свет. При протекании тока через ЖК вследствие анизотропии их электропроводности возникает объемный заряд, взаимодействующий с внешним полем $E$, что приводит к электрогидродинамической неустойчивости. В поляризационном микроскопе видны периодические системы темных и светлых полос из-за модуляции коэффициента преломления. Увеличение $E$ вызывает появление более сложных картин. Неустойчивости стационарного типа сменяются нестационарными, а затем наблюдается чрезвычайно сильное рассеяние света из-за турбулентности и возмущений ориентации ЖК (динамическое рассеяние света) $[1,2]$.

Эффект динамического рассеяния обычно имеет место в ЖК с отрицательной диэлектрической анизотропией, поскольку, с точки зрения стандартной модели, необходимым условием возникновения электроконвективной неустойчивости является положительный знак анизотропии проводимости [3]. На основании многочисленных экспериментальных исследований и теоретических расчетов было установлено, что для возникновения динамического рассеяния света необходимо выполнение следующих условий. Толщина слоя ЖК должна быть не меньше $6 \mu \mathrm{m}$, удельное сопротивление нематического жидкого кристалла (НЖК) должно быть не более $10^{7} \Omega \cdot \mathrm{m}$, диэлектрическая анизотропия должна быть отрицательной, частота возбуждающего напряжения не должна превышать критическую частоту релаксации пространственного заряда, анизотропия электропроводимости должна составлять $\sigma_{\|} / \sigma_{\perp}=1.5 \ldots 2$ [4-11].

В качестве основы при создании жидкокристаллических рассеивающих смесей могут быть использованы материалы МББА, ЖК-404, ЖК-404И, ЖК-440, ZLI-4330 LC и другие, обладающие широким температурным интервалом нематической фазы, малой отрицательной диэлектрической анизотропией и приемлемым значением вязкости. Таблица характеристик наиболее часто используемых электроотрицательных ЖК приведена в работе [12]. Эффект динамического рассеяния используют в оптических затворах (шторы, жалюзи, световые сигнальные устройства). Недостатком устройств, работающих на этом эффекте, является требование большого управляющего напряжения.

Несмотря на широкое использование эффекта рассеяния, влияние на характер процесса граничных условий до сих пор, насколько нам известно, никем подробно не исследовалось ни теоретически, ни экспериментально. Более того, для упрощения задачи и исключения влияния электродных эффектов вместо постоянного электрического поля в большинстве работ вообще использовалось низкочастотное переменное. Это в принципе меняет сценарий возникновения неустойчивостей, поскольку в постоянных электрических полях происходит разделение зарядов, приводящее к образованию неоднородных полей [13]. Между тем неустойчивости инжекционного типа, имеющие место в постоянных полях, обладают рядом интересных особенностей. При их рассмотрении игнорировать эффекты на межфазных 
границах невозможно. Именно исследованию барьерных эффектов и влиянию их на процесс динамического рассеяния посвящена настоящая работа.

Нами было замечено, что часть ячеек, заполняемых ЖК-440 с отрицательной диэлектрической анизотропией, демонстрирует аномальную зависимость интенсивности рассеяния от постоянного напряжения: при определенных напряжениях (в нашем случае 20-40 V в зависимости от толщин слоев ЖК и ориентанта) рассеяние прекращается, и ячейка вновь просветляется. При этом в ячейках с несимметричными граничными условиями просветление может наблюдаться только при одной полярности. Небольшое уменьшение интенсивности оптического рассеяния при увеличении напряжения наблюдали и другие авторы [14], однако форма кривых пропускания никак не обсуждалась.

\section{Эксперимент}

Были изготовлены ячейки, представляющие собой плоские капилляры с толщиной слоя ЖК 10-20 $\mu \mathrm{m}$, заполненные ЖК-440, в которых прозрачные электроды ITO (оксид индия-олова) покрывались различными ориентирующими слоями, обеспечивающими различные углы наклона директора ЖК в отсутствие напряжения. В качестве базовых вариантов были отобраны ячейки с симметричными граничными условиями с гомеотропной (хромолан) и параллельной плоскостям подложек (кварц $\left(\mathrm{SiO}_{2}\right)$, полиимид $(\mathrm{PI})$ и аморфный углерод $(a: \mathrm{C}-\mathrm{H}))$ начальной ориентацией директора. Мы сознательно не называем параллельную подложкам ориентацию планарной, поскольку планарная ориентация подразумевает создание в плоскости выделенного направления, например, посредством натирки. Нам же для исследования барьерных эффектов требовался геометрически гладкий, без какого-либо пространственного рельефа электрод. Кроме того, напыленные слои не обладали достаточной механической прочностью и в процессе натирки возникали области непокрытого ITO, что вело к полному исчезновению наблюдаемого нами эффекта просветления.

Для сравнения приводится ячейка с чистыми электродами, начальная ориентация директора в которой была неопределенной вследствие слабого сцепления ЖК с подложкой. Были изготовлены также гибридные ячейки с гомеотропной ориентацией ЖК вблизи одной подложки и параллельной - вблизи другой (хромолан- $\mathrm{SiO}_{2}$ и хромолан- $a: \mathrm{C}-\mathrm{H})$. Прозрачные электроды ITO изготавливались методом катодного распыления с последующим отжигом при атмосфере при $450^{\circ} \mathrm{C}$ (толщина порядка $150 \mathrm{~nm}$ ), поликристаллическая пленка кварца наносилась лазерным вакуумным испарением (толщина порядка $50 \mathrm{~nm}$ ). Аморфный углерод $a: \mathrm{C}-\mathrm{H}$ осаждался из газовой фазы по CVD (chemical vapor deposition) технологии, описанной в [15]. Слои хромолана и полиимида наносились методом центрифугирования с по- следующим высушиванием при температуре $180^{\circ} \mathrm{C}$. Растворителем хромолана служил изопропиловый спирт, а полиимида - диметилформамид.

Зависимость оптического пропускания ячеек от напряжения снималась на спектрофотометре СФ-56 на длине волны $650 \mathrm{~nm}$, ширина щели $6 \mathrm{~nm}$, расстояние между приемником и образцом составляло $20 \mathrm{~cm}$. ВАХ снимались с помощью цифрового мультиметра RIGOL DM3061. На приборе KEYSIGHT E4980A измерялись диэлектрические потери образцов на переменном токе с частотой $300 \mathrm{~Hz}$. Визуально картина образования и переориентации доменов наблюдалась в оптический микроскоп Carl Zeiss, Jenapol, микрофотографии сделаны с помощью камеры Levenhuk C800 NG.

\section{Результаты и обсуждения}

В ячейках, ориентированных гомеотропно с помощью хромолана, при повышении постоянного напряжения последовательно наблюдалась в микроскоп классическая картина. Ориентационные эффекты сменялись возникновением в системе электроконвекции первичных неустойчивостей, а при $E>2 \mathrm{~V} / \mu \mathrm{m}$ картина принимала вид кипящей жидкости, что соответствует переходу в режим динамического рассеяния света.

В ячейках, изначально ориентированных параллельно (кварц, полиимид), до напряжений, при которых появляется ионный ток и возникают роллы, не происходило никаких изменений. Далее, как и в предыдущем случае, наблюдалось появление неустойчивостей в виде двух типов наклонных роллов: zig и zag, которые образуют углы наклона $\sim 120^{\circ}$ друг с другом. Причиной образования наклонных роллов, как известно, является флексоэлектрический эффект. Далее структура теряет устойчивость и возникает продольная (т.е. вдоль директора n) мода доменных осцилляций (рис. $1, a$ ). Наибольшей интенсивности азимутальная мода доменных осцилляций достигает в режиме генерации фазовых волн. Частота азимутальных осцилляций растет с увеличением приложенного напряжения, а линейные размеры доменов уменьшаются. С ростом напряжения невозмущенных областей, по которым могли бы распространяться фазовые волны, практически не остается. В таком режиме противофазных блочных осцилляций доменная структура напоминает „паркет“(рис. 1,b). При дальнейшем увеличении напряжения частота осцилляций уменьшается, размеры доменов несколько увеличиваются и одновременно уменьшается контраст наблюдаемой картинки границы доменов как будто тают. В конце видны только узлы стоячих волн как темные точки на светлом фоне (рис. $1, c)$, затем исчезают и они.

Процесс перехода от стационарной доменной структуры к турбулентности в системе электроконвекции НЖК под действием постоянного электрического поля был подробно исследован в работах $[10,13]$. В тех случаях 

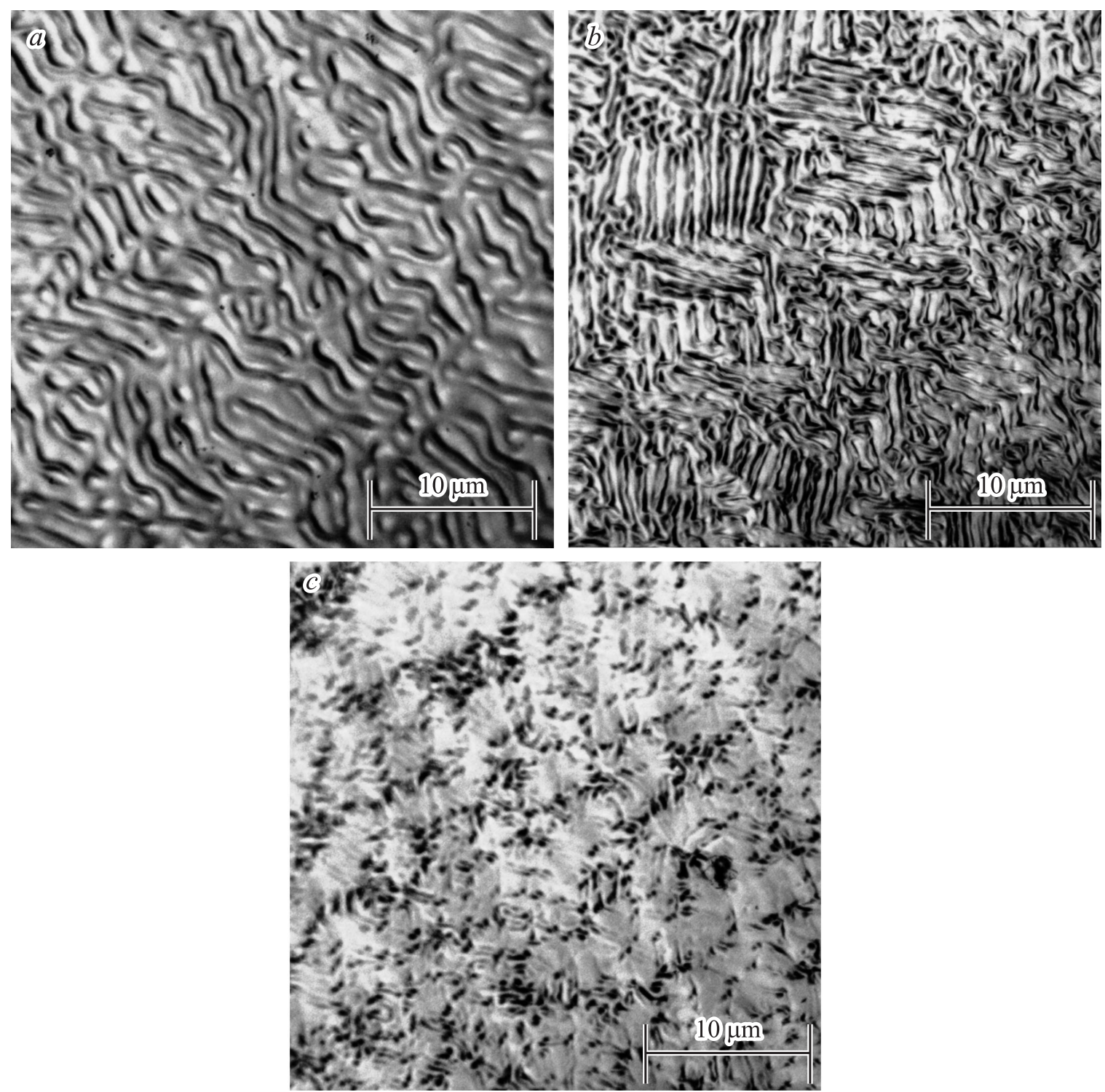

Рис. 1. Микрофотографии роллов, образующихся в ЖК ячейке с покрытыми $\mathrm{SiO}_{2}$ электродами: $a-0.8, b-3.2, c-5.0 \mathrm{~V} / \mu \mathrm{m}$.

и для тех режимов, когда зависимостью граничных условий от напряжения можно пренебречь, наши результаты не являются качественно новыми. До тех пор пока проводимость системы остается выше критического значения, последовательность наблюдаемых нами режимов очень похожа на наблюдаемую нашими предшественниками, за исключением псевдогексогональной решетки при относительно небольших напряжениях. Возможно, выпадение этого режима связано с отсутствием натирки, т.е. создания выделенного направления в плоскости подложек.

Мы исходили из соображений, что начальная ориентация директора (в отсутствие внешнего поля) в ячейках, заполняемых ЖК с $\Delta \varepsilon<0$, не играет принципиальной роли. Если изначально ЖК был ориентирован гомеотропно, то под влиянием внешнего поля происходит разворот диполей, и ориентация меняется на планарную, являющуюся исходной для возникновения неустойчивостей. Одновременно сильное электрическое поле генерирует поток ионов, и через кристалл начинает течь ионный ток. Нами были исследованы ячейки с обеими типами начальной ориентации директора и показано, что этот фактор не оказывает определяющего влияния на интенсивность рассеяния, особенно в сильных полях. В литературе также встречаются как планарный $[10,12,13]$, так и гомеотропный $[12,14]$ типы начальной ориентации. Тем не менее сценарий возникновения неустойчивостей несколько отличается в зависимости от того, была ли начальная ориентация задана гомеотропной или планарной. Очевидно, различия могут возникать также в зависимости от того, была ли задана определенная ориентация в плоскости подложек или нет.

Основной новый результат - переход системы в устойчивое состояние при высоких напряжениях за счет 


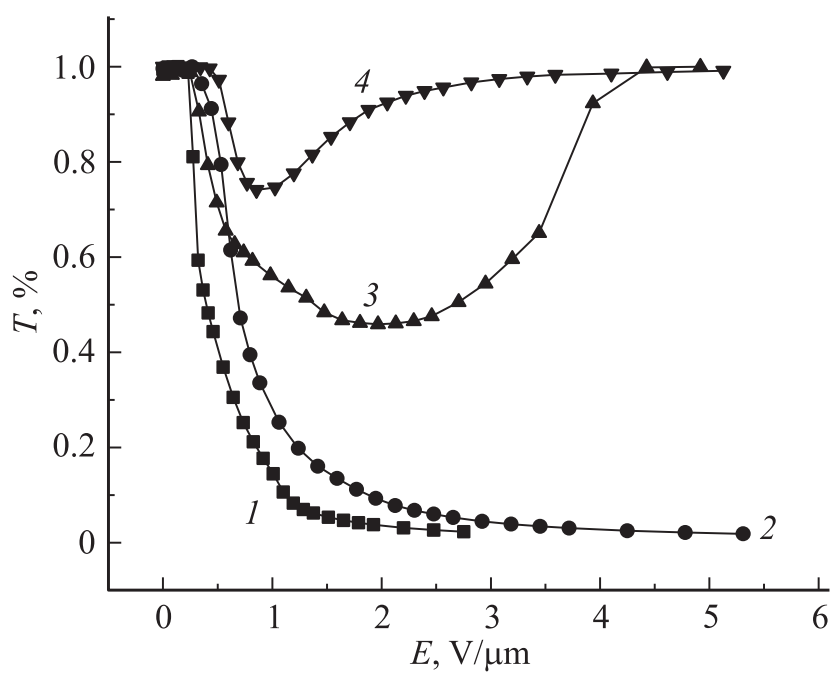

Рис. 2. Зависимости оптического пропускания ячеек от напряженности электрического поля: 1 - ITO, 2 - хромолан, 3 $\mathrm{SiO}_{2}, 4$ - PI.

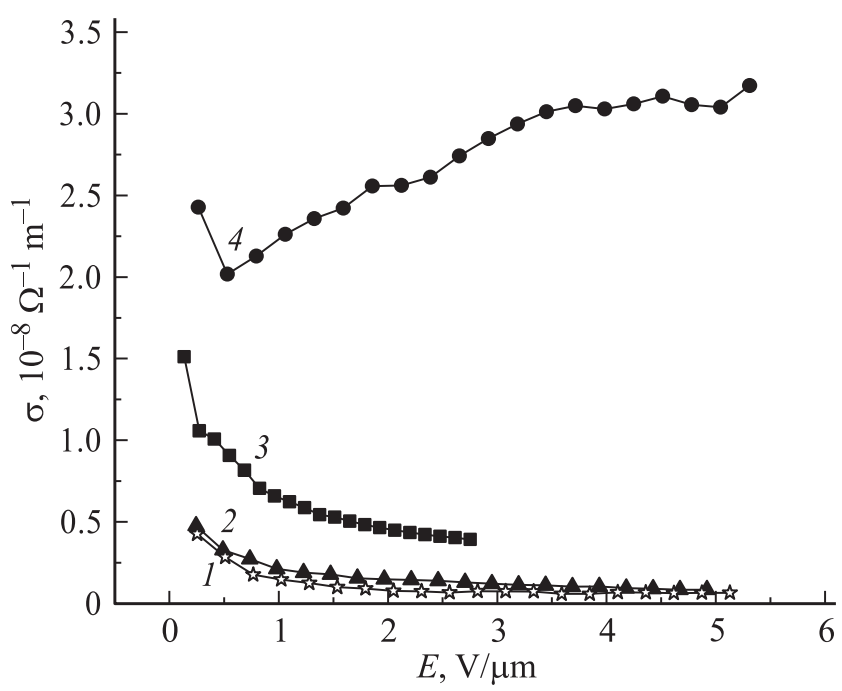

Рис. 3. Зависимости удельной проводимости ячеек от напряженности электрического поля: $1-\mathrm{PI}, 2-\mathrm{SiO}_{2}, 3-$ ITO, 4 - хромолан.

снижения проводимости с ростом напряжения. Из режима противофазных блочных осцилляций (рис. 1,b) при увеличении напряжения система не переходит в режим турбулентности, как предсказывает классическая теория [3] и наблюдалось экспериментально [10], но и не возвращается к порогу устойчивости, изображенному на рис. 1, $a$. Вместо этого наблюдается уменьшение амплитуды осцилляций (рис. 1,c) вплоть до полного прекращения электроконвекции и выхода системы в устойчивое состояние. Этот переход сопровождается прекращением рассеяния света и оптическим просветлением ячейки.

Зависимости оптического пропускания ячеек от напряженности электрического поля представлены на рис. 2, а зависимости их удельной проводимости - на рис. 3. Результаты представлены только для одной полярности, поскольку при симметричных граничных условиях картина инвариантна при смене знака напряженности поля. Видно, что в ячейках с непокрытыми электродами и с покрытыми хромоланом рассеяние более интенсивное, чем в ячейках, где электроды покрыты кварцем и полиимидом. Если для первых кратность ослабления света в направлении луча составляет порядка 40-50, причем максимум ослабления приходится на максимальное напряжение, то для вторых свет ослабляется в $1.2-3.5$ раза, после чего вновь наблюдается почти полное просветление (таблица). Сопоставляя результат с микроскопическими исследованиями, можно сказать, что ячейки с кварцем и полиимидом вообще не выходят в режим турбулентности, а слабое рассеяние наблюдается на доменных осцилляциях. Возможен и некий промежуточный вариант, если слой диэлектрика очень тонкий: ослабление достаточно сильное, но просветление при увеличении напряжения очень незначительное.

Что касается BAX, то для всех образцов за исключением образцов с использованием хромолана наблюдается сублинейный (замедленный) рост тока от напряжения, что возможно только, если с ростом напряжения падает проводимость (рис. 3). Если проводимость изначально не очень велика, то в какой-то момент она становится меньше критической величины, при которой еще наблюдаются неустойчивости, что и происходит в ячейках с низкой эмиссионной эффективностью эмитирующего электрода (катода). С другой стороны, при низких напряжениях проводимость ячеек с чистыми электродами и электродами, покрытыми хромоланом, выше, чем ячеек, электроды которых покрыты полиимидом или $\mathrm{SiO}_{2}$. Даже если падение проводимости с напряжением происходит по тому же закону, что и в ячейках с изолированными электродами, все равно она в достаточно широком интервале напряжений остается выше критической и рассеяние не прекращается.

Теперь о причинах возникновения и падения электрической проводимости в ЖК. Как уже говорилось, на границах ЖК с электродом существует энергетический барьер, препятствующий инжекции электронов из электрода в ЖК при малых напряжениях. Мы говорим конкретно об инжекции, поскольку применяемый в большинстве ЖК устройств в качестве прозрачного электрода ITO является электронным полупроводником. Рассмотрим два встречно включенных перехода на границах ЖК при приложении постоянного напряжения, сравнимого с высотой барьера (рис. 4). Как только внешнее электрическое поле снижает барьер, из инжектирующего электрода, включенного в прямом направлении, начинается полевая эмиссия электронов в ЖК. Поскольку свободные электроны в ЖК существовать не могут, они захватываются молекулами примесей, ионизуя их. Если ЖК „слишком хорошо“ очищен, то для увеличения проводимости и усиления рассеяния в него вносятся добавки акцепторного типа, способные присоединять 
Параметры ячеек

\begin{tabular}{|c|c|c|c|c|c|c|c|}
\hline № & Структура & $\begin{array}{c}D_{L C}, \\
\mu \mathrm{m}\end{array}$ & $\begin{array}{c}U(\min ) \\
\mathrm{V}\end{array}$ & $\begin{array}{c}\text { Кратность } \\
\text { ослабления }\end{array}$ & $\begin{array}{c}\sigma \text { при } 3 \mathrm{~V}, \\
\Omega^{-1} \mathrm{~m}^{-1}\end{array}$ & $\begin{array}{c}\sigma \text { в минимуме } \\
\text { пропускания } \\
\Omega^{-1} \mathrm{~m}^{-1}\end{array}$ & $\begin{array}{c}\operatorname{tg} \delta \text {, диэлектрические } \\
\text { потери на частоте } \\
300 \mathrm{~Hz}\end{array}$ \\
\hline 19 & ITO-ITO & 21.8 & 60 & 40 & $1.15 \cdot 10^{-8}$ & $3.9 \cdot 10^{-9}$ & 0.31 \\
\hline 20 & $\begin{array}{c}\text { Хромолан } \\
- \text { хромолан }\end{array}$ & 11.3 & 60 & 50 & $2.43 \cdot 10^{-8}$ & $3.17 \cdot 10^{-8}$ & 1.29 \\
\hline 22 & $\mathrm{SiO}_{2}-\mathrm{SiO}_{2}$ & 12.2 & 25 & 2 & $4.7 \cdot 10^{-9}$ & $1.5 \cdot 10^{-9}$ & 0.11 \\
\hline 23 & PI-PI & 11.7 & 10 & 1.34 & $5 \cdot 10^{-9}$ & $1.5 \cdot 10^{-9}$ & 0.14 \\
\hline 33 & $\begin{array}{c}\text { Хромолан } \\
-\mathrm{SiO}_{2}\end{array}$ & 11.0 & $\begin{array}{l}24(\mathrm{Cr}+) \\
60(\mathrm{Cr}-)\end{array}$ & $\begin{array}{r}3.9 \\
31.8\end{array}$ & $\begin{array}{l}3.6 \cdot 10^{-8} \\
1.6 \cdot 10^{-8}\end{array}$ & $\begin{array}{l}1.3 \cdot 10^{-8} \\
3.9 \cdot 10^{-8}\end{array}$ & 2.19 \\
\hline 37 & $\begin{array}{c}\text { Хромолан } \\
-a: \mathrm{C}-\mathrm{H}\end{array}$ & 11.5 & $\begin{array}{l}33(\mathrm{Cr}-) \\
60(\mathrm{Cr}+)\end{array}$ & $\begin{array}{l}6.28 \\
6.76\end{array}$ & $\begin{array}{l}2.67 \cdot 10^{-8} \\
2.03 \cdot 10^{-8}\end{array}$ & $\begin{array}{l}1.02 \cdot 10^{-8} \\
6.58 \cdot 10^{-8}\end{array}$ & 9.4 \\
\hline
\end{tabular}

электрон [16]. Отрицательно заряженные ионы дрейфуют по направлению к положительному электроду, т.е. через ЖК начинает течь ионный ток. На положительном электроде происходит экстракция электронов обратно в цепь, а нейтральные атомы примесей диффундируют под действием градиента концентрации обратно. Но на пути электронов существует препятствие - барьер на экстрагирующем электроде. Со стороны ЖК высота барьера с напряжением практически не меняется. Зато в ITO отданные ионами электроны попадают в область положительного объемного заряда, возникающего изза оттока электронов от границы, обладающей повышенным сопротивлением. При этом область объемного заряда и его сопротивление возрастают с увеличением обратного смещения.

Нанесение на электрод слоя диэлектрика в большинстве случаев повышает барьеры. Однако, поскольку ориентирующие слои делаются достаточно тонкими (десятки нанометров), в сильных полях возможно туннелирование сквозь них электронов.

Помимо высоты барьеров ориентант может влиять и на концентрацию примесей в ЖК, так как возможен его

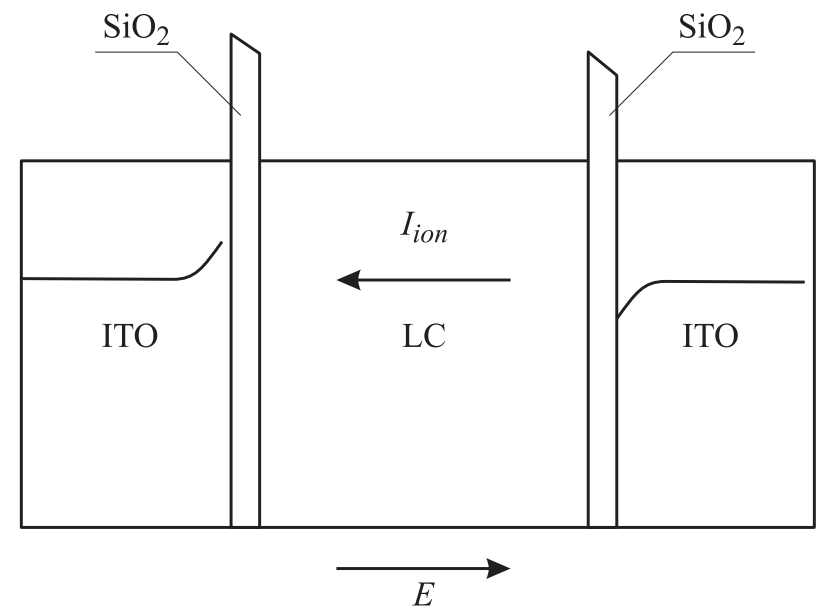

Рис. 4. Схема протекания тока через жидкий кристалл. Оба электрода покрыты слоем кварца. электролитический распад в сильных электрических полях. Это приводит к появлению дополнительных ионов и к возникновению более сильных токов, чем в случае чистого электрода, хотя барьеры на границах не снижаются. Этот эффект мы наблюдали в ячейках, где ЖК был ориентирован хромоланом. Хромолан представляет собой хромовую соль стеариновой кислоты. По своим химическим свойствам хромолан является катионоактивным веществом, т.е. при растворении распадается на положительно заряженный радикал и отрицательно заряженный кислотный остаток. Проводимость ячейки с хромоланом с напряжением растет (рис. 3). При этом ток с чистого электрода ITO ограничивается объемным зарядом и растет замедленно с выходом на насыщение, а проводимость вообще падает. В случаях с покрытием электрода изолирующими слоями кварца и полиимида удельная проводимость с ростом поля также уменьшается в результате повышения высоты барьера и увеличения сопротивления слоя объемного заряда.

Наши предположения о влиянии на ионные токи в ЖК барьеров на границах раздела фаз и распада хромолана подтверждают характеристики ячеек с несимметричными граничными условиями, рассеяние в которых кардинально зависит от полярности прикладываемого напряжения (рис. 5,a). Продемонстрировать влияние высоты барьера на инжектирующем электроде (катоде) на токи достаточно просто, поскольку почти любой диэлектрик повышает барьер и, кроме того, высоту барьера можно регулировать напряжением. Для ячейки хромолан-кварц при отрицательной полярности на $\mathrm{SiO}_{2}$ просветление с ростом напряжения наблюдается, а при положительной - нет, что подтверждает наше предположение об ограничении тока слабой инжекцией электронов в ЖК через слой $\mathrm{SiO}_{2}$ (рис. 5, a, кривая 1). Также подтверждается наше предположение о частичном распаде хромолана. Влияние хромолана проявляется тогда, когда на него подается положительный потенциал, т.е. в увеличение удельной проводимости вносят вклад положительно заряженные радикалы, делая ее биполярной. 

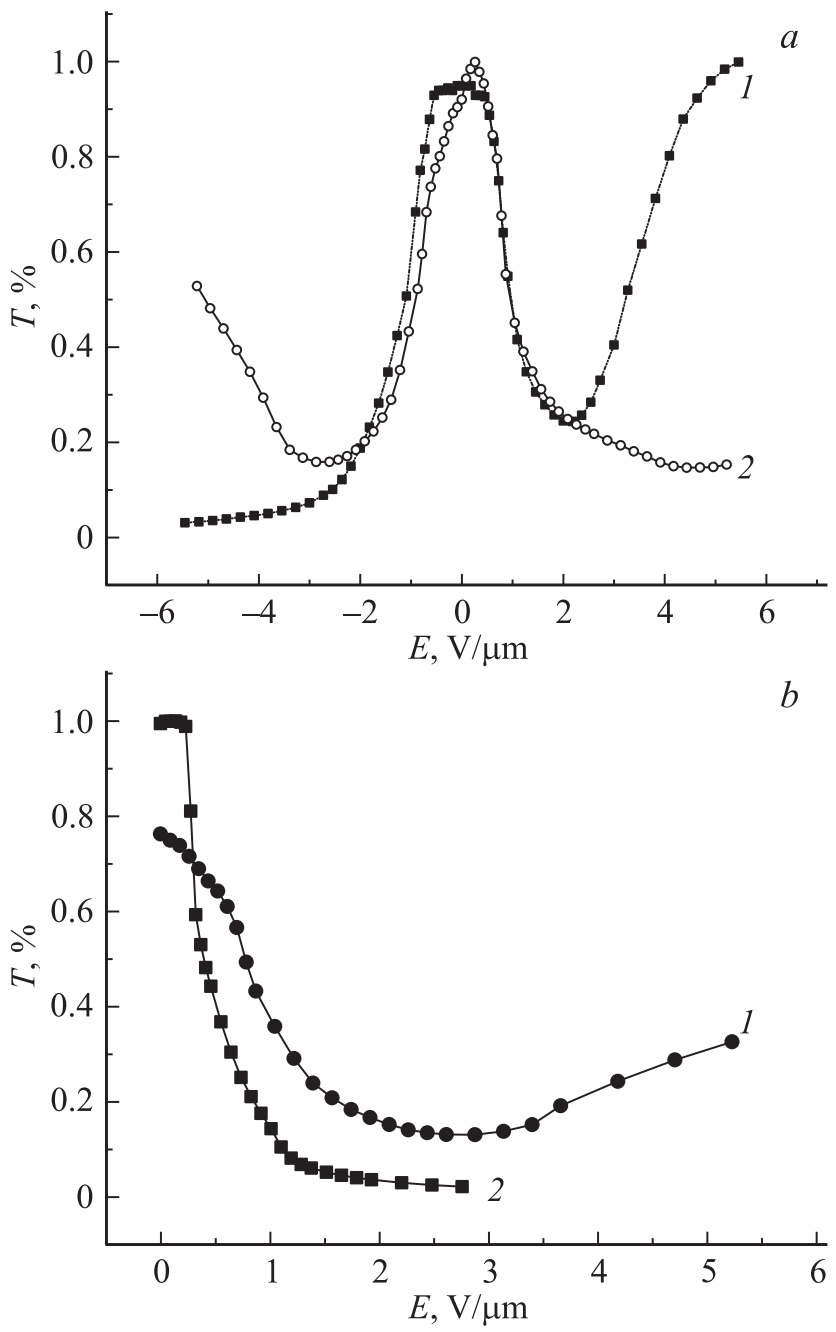

Рис. 5. $a-$ зависимость оптического пропускания ячеек с асимметричными граничными условиями от напряженности электрического поля: $1-$ хромолан- $\mathrm{SiO}_{2}$, $2-$ хромолан $-a-\mathrm{C}: \mathrm{H}$. Положительное напряжение соответствует плюсу на хромолане; $b-$ зависимость оптического пропускания ячеек с чистым эмитирующим электродом ITO (2) и с покрытым тонким слоем $a$-C:H (1).

С экстрагирующим электродом (анодом) сложнее. Так как его высота со стороны ЖК не зависит от напряжения, менять ее можно только технологически, подбором соответствующего покрытия. Нужно было подобрать для покрытия электродов химически устойчивое вещество, обладающее слабым сродством к электрону, но, в то же время, сцепление которого с ЖК достаточно сильное. В качестве такого вещества был опробован аморфный углерод $a-\mathrm{C}: \mathrm{H}$.

Известно, что алмаз является прекрасным материалом для автоэмиссионных катодов [17]. Преимуществом алмазного катода является не только высокая дрейфовая скорость носителей тока и электрическая прочность кристаллов. Перспективны его уникальные электронно-эмиссионные свойства, связанные с отри- цательным электронным сродством, которое является естественным состоянием поверхности (111) и устойчиво до температуры $T>900^{\circ} \mathrm{C}$ [18]. По этой причине у катодов с алмазным типом гибридизации связей валентных электронов атомов углерода наблюдается такое же снижение работы выхода электронов, как и для „открытых“ углеродных нанотрубок с графитовым типом структуры [19]. Особые надежды возлагаются на проявление в наноалмазных автоэмиссионных эмиттеpax, кроме уже названных традиционных свойств алмаза, присущих массивному кристаллическому состоянию, квантовых эффектов, характерных для низкоразмерных систем [20]. Большим преимуществом осаждаемых в разряде углеродных слоев является возможность варьирования их физических и химических свойств в очень широких пределах в зависимости от условий осаждения. Возможно получение всего спектра свойств: от широкозонных изолирующих алмазоподобных пленок до сравнительно узкозонных проводящих, приближающихся по свойствам к графиту [15]. Малое электронное сродство пленок аморфного углерода означает не только высокую эмиссионную эффективность при использовании в качестве катода, но и крайнюю неэффективность сбора электронов при использовании в качестве анода. Такой анод отталкивает электроны, что эквивалентно повышению для них барьера. В качестве ориентанта для ЖК $a$-С:Н также успешно применяется $[21,22]$.

На примере ячейки хромолан-аморфный углерод видно (рис. 5, $a$, кривая 2), что барьер на экстрагирующем электроде оказывает влияние на проводимость и соответственно на процесс рассеяния. Если барьер настолько высок, что электроны со стороны ЖК не могут его преодолеть, то протекание тока становится невозможным. Если экстрагирующий электрод покрыть слоем изолирующего широкозонного аморфного углерода $a$-C:H, то рассеяние вообще не наблюдается, независимо от покрытия инжектирующего электрода. При использовании для покрытия анода более узкозонной углеродной пленки наблюдается ограничение тока в цепи процессом экстракции электронов. Кривая зависимости оптического пропускания от напряжения при этом оказывается зеркально симметричной той, где ограничивающим фактором является эмиссия из катода (рис. 5,a). Зависимости удельной проводимости ячеек от напряжения обеих полярностей, представленные на рис. 6, подтверждают, что просветление, как и в случае симметричных ячеек, связано с уменьшением удельной проводимости ниже критической величины.

Доказательством того факта, что причиной просветления в случае покрытия анода аморфным углеродом является именно слабая экстракция электронов обратно в цепь, являются очень высокие диэлектрические потери, тангенс угла которых на частоте $300 \mathrm{~Hz}$ равен 9.4. Такие значения потерь свидетельствуют о высокой концентрации в ЖК заряженных ионов. Другими словами, ни концентрация примесей в ЖК, ни эмиссионная эффективность катода не являются в данном случае 

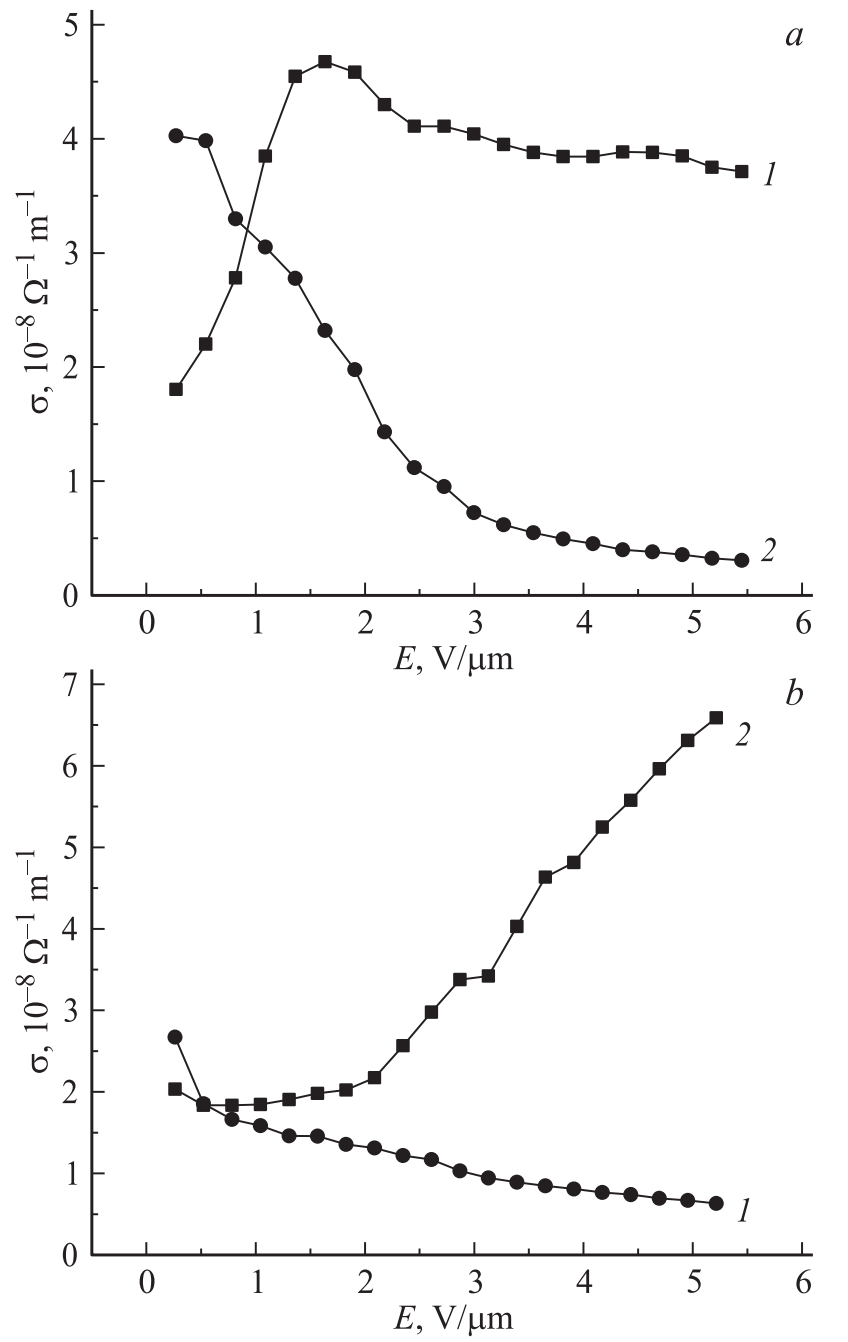

Рис. 6. Зависимость удельной проводимости ячеек хромолан- $\mathrm{SiO}_{2}(a)$ и хромолан- $a-\mathrm{C}: \mathrm{H}(b)$ от напряженности электрического поля. Кривые 1 - минус на хромолане, $2-$ плюс.

лимитирующим фактором для плотностей ионных токов. Для сравнения диэлектрические потери при покрытии обоих электродов хромоланом и кварцем составляют 1.29 и 0.11 соответственно (см. таблицу).

В случае покрытия алмазоподобной пленкой катода обращает на себя внимание отсутствие порога у эффекта рассеяния (рис. $5, b$ ). Это свидетельствует о том, что пленка $a-\mathrm{C}: \mathrm{H}$ обладает меньшей работой выхода, чем чистый ITO и тем более кварц или полиимид. Однако меньшая работа выхода не приводит к большей эмиссионной эффективности, поскольку по причине плохой электрической проводимости алмазоподобных пленок отсутствует механизм транспорта электронов к поверхности. При высоких напряженностях поля количество электронов, выходящих из ITO в ЖК через барьер $a-\mathrm{C}: \mathrm{H}$ и туннелирующих сквозь него, меньше, чем из непокрытого электрода. Видно, что уже при напряженностях поля более $0.5 \mathrm{~V} / \mu \mathrm{m}$ интенсивность рассеяния становится меньше, чем в случае с непокрытым катодом, а при больших напряженностях даже наблюдается тенденция к просветлению. В настоящее время известны способы повышения инжекционной эффективности плоского алмазоподобного ненакаливаемого катода (легирование либо создание композитных алмазно-графитовых пленок), однако рассмотрение этого вопроса выходит за рамки настоящей работы.

\section{Заключение}

Из изложенного следует, что прекращение электроконвекции и переход системы в устойчивое состояние при высоких напряжениях, сопровождающийся прекращением рассеяния света и оптическим просветлением ячейки, происходит за счет снижения проводимости ниже критического уровня с ростом напряжения. Просветление НЖК с отрицательной диэлектрической анизотропией с увеличением напряженности постоянного электрического поля наблюдается вследствие роста сопротивления объемного заряда на экстрагирующем электроде. Оно наблюдается в тех ячейках, проводимость которых в относительно слабых полях близка к минимально возможной для возникновения электрогидродинамических неустойчивостей. При этом малая проводимость, в свою очередь, может быть обусловлена тремя причинами: недостаточным количеством нейтральных примесей в ЖК, слабой эмиссией электронов из катода и, наконец, высоким барьером со стороны ЖК на аноде, из-за чего электроны не могут попасть обратно в цепь. Первая причина обычно не связана с граничными условиями. Исключением является распад материала покрытия электродов на заряженные радикалы под воздействием поля.

Высоты барьеров на обоих электродах зависят от материалов покрытий этих электродов. Подавляющее большинство диэлектриков, будучи нанесенными на ITO, повышают работу выхода из него и тем самым снижают эмиссионную эффективность катода. Исключение составляют покрытия, обладающие крайне низким, или даже отрицательным, сродством к электрону. Высота барьера для электронов на экстрагирующем электроде (аноде) со стороны ЖК не меняется с напряжением, поэтому здесь возможны только два случая. Либо через барьер протекают токи, ограниченные объемным зарядом со стороны ITO, либо токи не регистрируются вообще ни при каких напряжениях. Пограничная ситуация, когда экстракция электронов идет, но очень слабо, в результате чего в ЖК скапливается большое количество ионов, была реализована нами с целью иллюстрации влияния на ионные токи высоты барьера на аноде.

Полученные результаты следует иметь ввиду при проектировании жидкокристаллических ограничителей излучения на эффекте рассеяния, проводимость которых закладывается близкой к предельной для увеличения срока службы. Можно рекомендовать снижать уровень допирования ЖК примесями, а нужных плотностей тока 
достигать за счет увеличения эмиссионной эффективности катода, например, путем покрытия его алмазнографитовой пленкой. Использование такого катода позволит не только увеличить срок службы электрооптического модулятора, но и снизить его рабочее напряжение.

Работа выполнена при государственной финансовой поддержке ведущих университетов Российской Федерации (субсидия 074-U01).

\section{Список литературы}

[1] Блинов Л.М. / УФН. 1974. Т. 114. Вып. 1. С. 67-96.

[2] Блинов Л.М. Жидкие кристаллы: Структура и свойства. М.: Книжный дом ЛИБРОКОМ, 2013. 480 с.

[3] Де Жен П. Физика жидких кристаллов. М.: Мир, 1977, $400 \mathrm{c}$.

[4] Baise A., Teucher I., Labes M. // Appl. Phys. Lett. 1972. Vol. 21. N 4. P. $142-143$.

[5] Хаткевич В.И., Пинкин С.А., Тихомирова Н.А., Зейналлы A.X. // Письма в ЖЭТФ. 1978. Т. 28. Вып. 1. С. 13-16.

[6] Barret S., Gaspard F., Herino R., Mondon F. // J. Appl. Phys. 1976. Vol. 47. N 6. P. 2375-2377.

[7] Barret S., Gaspard F., Herino R., Mondon F. // J. Appl. Phys. 1976. Vol. 47. N 6. P. 2378-2381.

[8] Hérino R. // J. Appl. Phys. 1981. Vol. 52. N 5. P. 3690-3692.

[9] Федоряко А.П., Кочержин А.И., Кухтин М.П., Черняков Э.И. // Радиотехника. 2013. Вып. 175. С. 53-57.

[10] Делев В.А., Скалдин О.А., Батыршин Э.С., Аксельрод Е.Г. // ЖТФ. 2011. Т. 81. Вып. 1. С. 11-18.

[11] Вальков А.Ю., Романов В.П., Шалагинов А.Н. // УФН. 1994. T. 164. № 2. C. 149-193.

[12] Bing-Xiang Li, Borshch V., Shiyanovskii S.V., Shao-Bin Liu, Lavrentovich O.D. // Appl. Phis. Lett. 2014. Vol. 104. P. 201105 (1-4).

[13] Батыршин Э.С., Крехов А.П., Скалдин О.А., Делев В.А. // Письма в ЖТФ. 2014. Т. 40. Вып. 24. С. 14-21.

[14] Geis M.W., Bos P.J. Liberman V., Rothschild M. // Opt. Expres. 2016. Vol. 24. N 13. P. 13812.

[15] Коншина E.A. Аморфный гидрогенизированный углерод и применение его в оптических устройствах. СПб: СПб НИУ ИТМО, 2010. $91 \mathrm{c}$.

[16] Mortimer M. Labes. Nematic liquid crystals with chargetransfer acceptors as dopants. United State Patent. N 380.817. July 19, 1973.

[17] Ябаров Р.К. // ЖТФ. 2006. Т. 76. Вып. 1. С. 42-48.

[18] Алмазы в электронной технике. Сб. ст. / Под ред. В.Б. Кваскова. М.: Энергоатомиздат, 1990. 248 с.

[19] Образиов А.Н., Павловский И.Ю., Волков А.П. // ЖТФ. 2001. Т. 71. Вып. 11. С. 89-95.

[20] Пчеляков О.П., Болховитянов Ю.Б., Двуреченский А.В. и др. // ФТП. 2000. Т. 34. Вып. 11. С. 1281-1299.

[21] Коншина Е.А., Федоров М.А., Амосова Л.П., Воронин Ю.М. // ЖТФ. 2008. Т. 78. Вып. 2. С. 71-76.

[22] Амосова Л.П., Чайка А.Н. // ЖТФ. 2010. Т. 80. Вып. 10. C. $129-136$. 